\title{
Diagnosis and management of acute puerperal bartholinitis caused by Escherichia coli
}

\author{
Helena Lucia Barroso dos Reis ${ }^{[1]}$, Carla Renata Petillo de Pinho ${ }^{[2]}$ \\ and Dennis de Carvalho Ferreira ${ }^{[2],[3]}$
}

[1]. Ambulatório de Ginecologia e Obstetrícia, Universidade Federal do Espírito Santo, Vitória, ES. [2]. Faculdade de Odontologia, Universidade Veiga de Almeida, Rio de Janeiro, RJ. [3]. Faculdade de Farmácia e de Enfermagem - Centro Universitário UNIABEU, Rio de Janeiro, RJ.

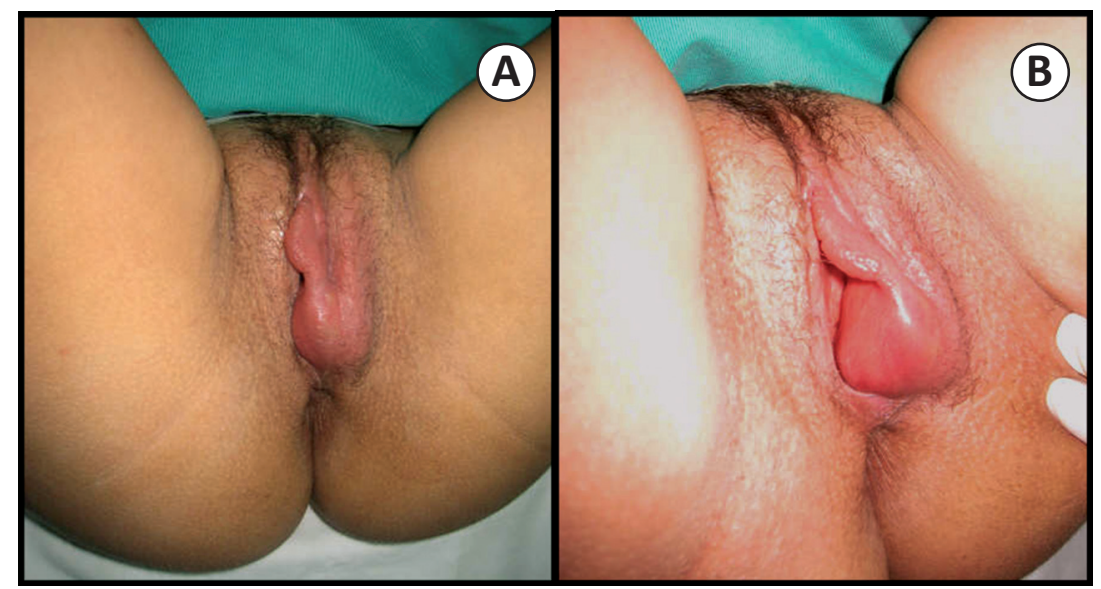

A 27-year-old, Caucasian, university-graduated, married, puerperal female patient who lived in the City of Vitoria, State of Espírito Santo, Brazil, presented with recurring genital moniliasis, without a medical history of underlying diseases. She underwent regular cytology exams, including cervical and vaginal samples that showed no atypia. Clinical evaluation also remained unchanged.

The test for Streptococcus agalactiae in the $37^{\text {th }}$ gestational week was negative. This primiparous patient underwent a cesarean section due to cephalo-pelvic disproportion 15 days prior to abscess drainage of the Bartholin's gland on the left side, which characterized a clinical case of acute bartholinitis.

The onset of this condition was an extremely painful tumor in the genital area five days after delivery. It was clinically detected as local redness, which started to bulge and then progressed to fluctuation (abscess) (Figures A and B). Other possible differential diagnostic hypotheses were Skene duct cysts, which are rare; epidermal inclusion cyst; and papillary hidradenoma, among other Bartholin's gland benign lesions. Abscess drainage was performed, and purulent secretion material was collected for culture, which evidenced growth of Escherichia coli. Oral antibiotic therapy (500mg cephalexin) was prescribed every six hours for seven days.

Remission of the Bartholin abscess at the end of the antibiotic therapy was observed. During the 5-year clinical follow-up in the gynecology assistance program up to now recurrence was not observed.

\section{REFERENCES}

1. Omole F, Simmons BJ, Hacker Y. Management of Bartholin's duct cyst and gland abscess. Am Fam Physician 2003; 68:135-140.

2. Fiori E, Ferraro D, Borrini F, De Cesare A, Leone G, Crocetti A, et al. Bartholin's gland hyperplasia. Case report and a review of literature. Ann Ital Chir 2013; 84 (ePub): pii: S2239253X13021774.

3. Wechter ME, Wu JM, Marzano D, Haefner H. Management of Bartholin duct cysts and abscesses: a systematic review. Obstet Gynecol Surv 2009; 64:395-404.

Address to: Dra. Helena Lucia Barroso dos Reis. Ambulatório de Ginecologia e Obstetrícia/UFES. Av. Marechal Campos 1468, Maruípe, 29043-260 Vitória, ES, Brasil.

Phone: 5527 3335-7180

e-mail: dr.hbarroso@gmail.com

Received 11 July 2014

Accepted 18 August 2014 